\title{
Prevalence of Thyroid Disorders in Pregnant Women In Hospital Tengku Ampuan Afzan \& International Islamic University Malaysia Medical Centre
}

Nurul Azyati Mohd Azemi ${ }^{1}$, Nur Afirah Zainal Abidin ${ }^{1}$, Adlina Nadhirah Mohd Amin ${ }^{1}$, Salmi Daraup ${ }^{1}$, Miza Hiryanti Zakaria ${ }^{2}$, Mohammad Arif Shahar ${ }^{3}$

${ }^{1}$ Department of Obstetric and Gynaecology, Kulliyyah of Medicine, International Islamic University Malaysia

${ }^{2}$ Department of Internal Medicine, Hospital Tengku Ampuan Afzan, Kuantan

${ }^{3}$ Department of Internal Medicine, Kulliyyah of Medicine, International Islamic University Malaysia

Presenter: Nurul Azyati Mohd Azemi

Introduction: Data on the burden of thyroid disease in pregnant women in our community is scarce albeit the detrimental effects it brought to both the mother and fetus if left untreated. The aim of this study was to determine the prevalence of thyroid disorders, socio-demography distribution, and method of diagnosis in pregnant women of both tertiary centres in Kuantan, Pahang. Materials and Methods: A retrospective cross sectional study involving patients under follow ups at the Endocrine and Obstetric Clinics of Hospital Tengku Ampuan Afzan (HTAA) and International Islamic University Malaysia Medical Center (IIUM MC) from the $1^{\text {st }}$ January until the $30^{\text {th }}$ June 2017. Out of 923 pregnant women, 29 were found to have thyroid disorders. Detailed demographic data and thyroid function test readings were taken from their medical records and thyroid status were determined from TSH and FT4 readings using the trimester-specific thyroid reference range. Results: The prevalence of thyroid disorders in both centres was $3.14 \%$, with specific prevalence of $2.80 \%$ for HTAA and $6.12 \%$ for IIUM MC. Nearly half of them were hyperthyroid (47.85\%), $17.4 \%$ was hypothyroid and Graves' disease dominated the diagnosis of thyroid disease (30.43\%). Significant association was found in weight changes with patients' thyroid status; reduction in weight in first trimester and increment in weight in second trimester were mainly seen in the hyperthyroid group $(\mathrm{p}<0.01, p=0.027)$. Conclusion: The acceptable prevalence of $3.14 \%$ for thyroid disorders in pregnancy could be contributed by the iodine availability in this community. High prevalence of Graves' disease warrants future screening for maternal thyroid stimulating immunoglobulin amongst hyperthyroid women. 